\title{
Modelo de apropriação de tecnologia: caso da indústria de cerâmica vermelha
}

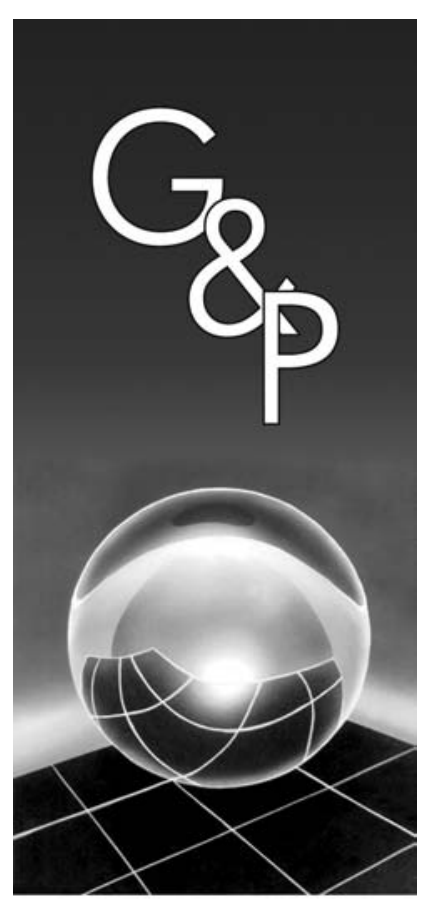

\author{
Simone de Sá Bastos \\ Marina Rodrigues Brochado
}

\section{Resumo}

O ritmo acelerado das inovações tecnológicas, nos últimos anos, tem causado impacto social, político, cultural, ecológico e econômico nas nações. Nos anos 1980/1990, uma comissão da ONU teve a responsabilidade de levantar os problemas que o Homem teria nas décadas vindouras, o que subsidiou a Conferência das Nações Unidas sobre Meio Ambiente e Desenvolvimento - ECO-1992. Neste encontro, 179 países assinaram uma agenda de compromissos para o século XXI, a Agenda XXI, e apresentaram a proposta de ecoeficiência para auxiliar as empresas no planejamento ambiental, abordando uma nova dimensão de competitividade: produzir com eficiência, utilizando menos insumos e gerando menos rejeitos. Além desta necessidade de conservação ambiental, o ser humano está exigindo que as empresas se apropriem das altas tecnologias - high tech - existentes em outros países. Contudo, dependendo do nível de desenvolvimento dos países, os empresários devem ter o cuidado para que os nativos usuários estejam preparados para absorver estas inovações. Este trabalho apresenta um modelo que investiga os caminhos necessários à apropriação de tecnologia e define uma metodologia de cálculo do nível tecnológico nas tomadas de decisão quanto à apropriação de inovação. O estudo de caso aplicado é da apropriação da tecnologia alemã de fabricação de tijolos estruturais de cerâmica vermelha de alta porosidade no Brasil. São identificadas lacunas - gaps - existentes entre a expectativa do cliente e a sua percepção em relação ao produto ofertado; estas lacunas delineiam o perfil tecnológico do produto. A experiência testa que, na Alemanha, o desenvolvimento da indústria cerâmica ocorreu pautado em base de sustentabilidade, enquanto, no Brasil, tal desenvolvimento ainda é tímido, se forem considerados os requisitos ambientais, principalmente no que diz respeito à equidade entre gerações quanto à eficiência energética. O teste do modelo demonstra que o processo de apropriação de inovação nas organizações deve ser implantado a partir de um processo de planejamento estratégico, que considere os ciclos de vida de tecnologia e futuras inovações, inferindo desta forma que a modelagem proposta auxilia o empresário quanto à apropriação de inovações tecnológicas de um ambiente sustentável.

Palavras-chave: Inovação. Cerâmica vermelha. Tecnologia apropriada.

\section{Introdução}

Nos anos 80 do século XX, uma comissão da ONU (BRUNDTLAND, 1986), presidida pela Sra. Gro Brundtland, da Noruega, teve a responsabilidade de levantar os problemas que o Homem teria para solucionar nas décadas vindouras. Este relatório mundial envolveu vários profissionais de todas as áreas, desde operários e intelectuais a políticos e religiosos, levou quase dois anos para ser concluído e recebeu o título de Nosso Futuro Comum. Então, a expressão 'meio ambiente' passou a englobar o ser humano como o seu principal objetivo e não apenas a natureza.
Este relatório foi tão importante que subsidiou a Conferência das Nações Unidas sobre Meio Ambiente e Desenvolvimento - ECO-92, ocorrida no Brasil, em 1992, quando 179 países assinaram uma agenda de compromissos para o século XXI, a Agenda XXI, em que concordaram com mudanças básicas e radicais em alguns procedimentos técnicos, sociais e econômicos adotados naqueles últimos tempos para um desenvolvimento sustentável do Planeta (COMISSÃO INTERMINISTERIAL PARA PREPARAÇÃO DA ECO-92, 1991). 
Dentro desse raciocínio, segundo o qual é preciso "abrasileirar" toda a cultura importada e, principalmente, pensar nos compromissos que devem ser assumidos no presente século, é que as pesquisas apresentadas foram desenvolvidas, propondo uma medida de nível tecnológico, para auxiliar nas tomadas de decisão quando da apropriação de inovações (GONZALEZ, 1998).

Atualmente, no sistema econômico mundial, a tecnologia é enfatizada a todo o momento e os países em desenvolvimento necessitam e buscam uma orientação de suas referências de desenvolvimento tecnológico. Esses países estão conscientes de que sua sobrevivência está ligada à alocação de seus recursos de uma maneira que estes sejam realmente valorizados e adaptados às suas necessidades. A inovação tecnológica, quando fruto de uma apropriação, passa, assim, por uma acomodação, uma adaptação, conforme vai sendo absorvida. No entanto, muitas vezes, a maioria dos empresários executa, apenas, a transferência de inovações como elas se apresentam nos países de origem, sem fazer a devida apropriação (PIRES, 2003).

Desta forma, neste trabalho, apresenta-se o estudo de caso de apropriação de tecnologia alemã de alta porosidade aplicada na produção do tijolo estrutural de cerâmica vermelha no Estado do Rio de Janeiro. Essa apropriação tecnológica está ocorrendo como resultado de um acordo de intercâmbio entre o Brasil e Alemanha, por meio do Centro Federal de Educação Tecnológica Celso Suckow da Fonseca (CEFET/RJ) e do Instituto de Tecnologias dos Trópicos (ITT), da Fachhochschule de Colônia. Conta, ainda, com as parcerias do Serviço de Apoio às Micro e Pequenas Empresas do Estado do Rio de Janeiro (SEBRAE-RJ), da Associação Nacional da Indústria Cerâmica (ANICER), do Instituto Nacional de Tecnologia (INT) e da Fundação de Apoio à Pesquisa do Estado do Rio de Janeiro (FAPERJ).

Este estudo permite a observação da inovação tecnológica aplicada ao contexto da tecnologia alemã de cerâmica vermelha estrutural de alta porosidade, relacionando os impactos socioeconômicos e ambientais da sua produção e da utilização nas edificações. O mesmo estudo esclarece enormes diferenças entre os países no mesmo setor e que possibilitam comparações, como:

A produtividade brasileira chega a 13.000 peças (bloco vazado de 8 furos 9x19x19 cm) por funcionário, enquanto a europeia chega, em média, a 200.000. Outra comparação é a de que a produtividade atual brasileira é a mesma da europeia em meados da década de 50 (SEBRAE, 1997; CEFET; SEBRAE; ANICER, 2003);

Blocos cerâmicos, lajes e telhas, na Alemanha, são produzidos a partir de um processo que reduziu em dez anos $40 \%$ do consumo energético médio do setor (WIENEBERGER, 1999);

O ciclo de queima em alta temperatura na indústria alemã é de duas horas (WAGNER, 1998 apud BROCHADO, 2001). Este ciclo na cerâmica vermelha convencional é de oito horas. O ciclo total, por sua vez, é de 24 horas, enquanto o da cerâmica vermelha convencional feita no Brasil é, em média, de 48 horas (SEBRAE, 1997).

Na Alemanha, depois do período da Segunda Guerra Mundial, as cidades alemãs ficaram totalmente destruídas e houve muita escassez de energia. Foi necessária a reconstrução das cidades e das edificações e, com o rigoroso clima no inverno daquele país, as habitações deveriam possuir um bom isolamento térmico, pois assim contribuiriam para a redução do consumo de energia usada com o aquecimento (RIMPEL, 1998). Para se incentivar o desenvolvimento desta tecnologia nas empresas privadas, foram necessárias políticas públicas rígidas, que resultassem em leis pró-ambientais específicas (Brochado et al., 2002). Assim, a questão básica é a seguinte: como apropriar uma nova tecnologia em um ambiente de inovação?

Na procura de responder à questão proposta e de participar das preocupações ambientais presentes em todo progresso globalizado do Planeta, este trabalho centraliza suas pesquisas na apropriação da tecnologia de alta porosidade aplicada a tijolos estruturais de cerâmica vermelha padrão alemão para o Estado do Rio de Janeiro, seguindo os indicadores apresentados no Fórum Econômico Mundial (FEM) em Davos, 2002. Esse encontro, anualmente realizado em Davos, na Suíça, reúne líderes políticos nacionais, presidentes, chefes de Estado, ministros, dirigentes de Bancos Centrais, executivos de corporações, intelectuais e demais personalidades de destaque na área socioeconômica e empresarial para debater questões referentes a diversas áreas, tais como governança corporativa, aquecimento global, problemas sociais e econômicos, e conflitos internacionais (PONTUAL, 2006).

Conforme Brochado (2000), a tecnologia alemã consiste na fabricação de um tijolo de alta qualidade, que desempenha três funções simultaneamente: a) construir alvenaria; b) estrutural, e c) isolamento térmico. Esta tecnologia, basicamente, combina um design que retarda o fluxo de calor através do tijolo, em função da sua geometria, que tem o formato do vazamento do tijolo, e a disposição deste. Os tijolos são projetados para dificultar a condução de calor através da peça, de maneira que o calor percorra uma distância maior no interior do tijolo, retardando-se o fluxo de calor na peça, como demonstra a Figura 1.

Conforme Brochado (2000), o mesmo efeito é conseguido reduzindo-se os pontos de condução de calor, o que é obtido pela diminuição da densidade do material cerâmico, a partir de adição de materiais combustíveis, que criam microporosidades no corpo cerâmico do tijolo. Os aditivos combustíveis auxiliam também durante o processo de queima da cerâmica, ajudando a reter o calor e auxiliando a queima no interior da peça. Após esta etapa, se extinguem, deixando espaços vazios que, dependendo da granulometria do material utilizado, geram porosidades de diferentes tamanhos e formas. 
Estes fatores combinados contribuem para a redução da condutibilidade térmica do tijolo e, como consequência, a redução da transmitância térmica nas alvenarias, promovendo a redução do consumo de energia tanto no processo de fabricação do tijolo de cerâmica vermelha, como na edificação de alvenaria construída com este tijolo.

Conforme o Autor, com a utilização desta tecnologia, tanto na Alemanha como no Brasil, será possível a aplicação do princípio 3 da Agenda XXI, que estabelece que tanto as gerações atuais quanto as futuras têm direito a encontrar equitativamente os mesmos recursos e bens ambientais, corroborando com o atual contexto de sustentabilidade. Portanto, à medida que se estabelece a equidade intergerações, o conforto térmico, a preservação ambiental e a eficiência energética, o longo ciclo de vida do produto tijolo sobreviverá às demais gerações. $\mathrm{O}$ empresário estará inovando tecnologicamente - ao modernizar alguns dos processos da produção da cerâmica vermelha - e se preparando para a competitividade.

O objetivo deste artigo é apresentar um modelo que investiga os caminhos necessários à apropriação de tecnologia e propor uma medida de nível tecnológico para que o empresário possa avaliar constantemente as expectativas do cliente no contexto da sustentabilidade e implementar as inovações necessárias e requisitadas por este, quando da apropriação de tecnologia.

O modelo apresentado contempla o levantamento dos atributos valorizados pelo empresário na percepção das expectativas do consumidor, quando da utilização do produto proposto segundo a filosofia do QFD (Quality Function Development), seguindo a modelagem conceitual de Qualidade em Serviço (PARASURAMAN; ZEITHAML; BERRY, 1985). Nessa modelagem, se identificam as lacunas - gaps - entre as percepções dos empresários em relação aos consumidores e, posteriormente, apresentam-se definições de ações de inovação pelos empresários.

A partir da observação das percepções dos empresários em relação à expectativa do consumidor, são detectados alguns gaps que podem ser tecidos em atenção à entrega de um produto. Para que a apropriação da inovação se dê dentro das diretrizes do desenvolvimento sustentável, o

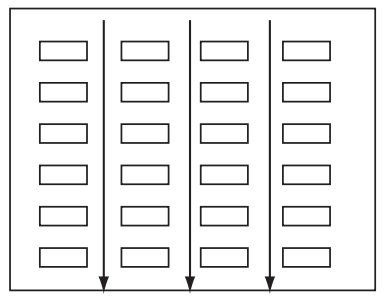

Design do tijolo de vedação brasileiro

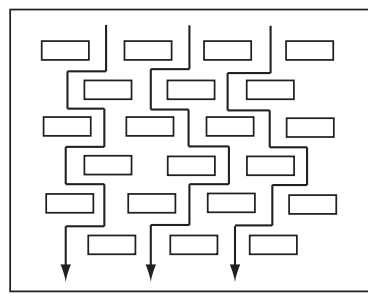

Design do tijolo estrutural alemão
Figura 1. Fluxo de calor no interior do tijolo estrutural de cerâmica vermelha de alta porosidade. Fonte: BROCHADO, 2000. empresário deve contemplar as expectativas do consumidor em relação a um produto e à percepção deste produto. Para tanto, é necessário estar atento aos itens determinantes essenciais para a percepção do nível tecnológico do produto ofertado.

\section{Apropriação de inovações}

Na natureza, todas as coisas têm um ciclo e, em todas as vezes que se renovam, há uma apropriação. O início de ação adaptativa é sempre uma quebra da já existente, ou seja, qualquer intervenção no fluxo suave e no detalhe da ação (MONTAÑA, 2002). Se nada se quebra ao redor, é porque tudo está se repetindo, indicando a existência de uma rotina pré-estabelecida.

Conceito: inovar vem do latim innovare, que literalmente significa renovar; na língua portuguesa, também apresenta este significado inovar, e acrescenta-se renovar, introduzir novidade. Segundo Freeman (1982, apud MONTAÑA, 2002), inovação na indústria inclui o desenho, a produção e as ações de venda que formam parte do marketing de um produto novo ou melhorado e, também, o primeiro uso comercial de um processo ou parte do equipamento produtivo novo.

Para inovar, é preciso que o empresário esteja disposto a reformular todo o pensamento que possa estar atrelado aos modelos de administração tradicionais e também a planejar com objetivos a longo e curto prazo, pois não basta mais pensar a solução ou dar um 'jeitinho', quando o problema aparece. As atitudes que, muitas vezes, eram tomadas pelo chefe, hoje são decididas em grupo, por estas interferirem na vida dos funcionários. A participação de funcionários nas resoluções de problemas empresariais está cada vez mais evidente, pois, além de terem suas ideias valorizadas, os chefes não assumem riscos sozinhos. $\mathrm{O}$ conhecimento e a informação capacitam os empregados à previsão das consequências e à opção pela que seja de menor dano (HORTA; RENATO, 2006).

No século XIX, com as novas correntes científicas, como o Determinismo, o ser humano era considerado um animal sujeito a forças que determinavam o seu comportamento: o meio, a hereditariedade, o instinto e o momento. $\mathrm{O}$ Homem era, então, produto do Meio em que vivia: Meio Ambiente $\rightarrow$ Homem (MARX; ENGELS, 1848).

O impacto do crescimento acelerado e do aumento populacional é visível em todo mundo. Para dar lugar às agriculturas, houve a necessidade de expansão territorial, o que ocasionou a devastação de florestas, propiciando o surgimento de áreas desérticas, favorecendo o aquecimento da temperatura terrestre, o chamado efeito estufa. Para resolver o problema da refrigeração, o homem criou, no final dos anos 30 do século XX, o CFC (clorofluorcarbono), a sintetização de algumas substâncias químicas, que causaram um buraco na camada de ozônio (Intergovernmental 
Panel on Change Climate - PCC). Enfim, percebeu-se que o mundo das futuras gerações estava ameaçado e as primeiras manifestações a favor da vida e do meio ambiente começaram a surgir. O Homem destruindo o Meio: Meio Ambiente $\leftarrow$ Homem.

Sob o título Nosso Futuro Comum, em 1987, a Sra. Gro Harlem Brundtland, da Noruega, presidente da Comissão Mundial sobre Meio Ambiente e Desenvolvimento, divulgou um relatório solicitado pela Assembleia Geral das Nações Unidas, que contivesse as primeiras orientações acerca de uma agenda global para mudança de hábitos. Neste relatório, a Sra. Gro estabeleceu os principais objetivos que o mundo deveria traçar para um futuro mais condizente com a possibilidade real de sobrevivência a partir do presente milênio (BRUNDTLAND, 1986).

Primeiramente, a Sra. Gro e os membros da Comissão observaram que os termos - meio ambiente e desenvolvimento - eram tratados com sentidos puramente ingênuos. O Meio Ambiente era entendido como "um conjunto de questões ambientais", sem levar em conta os aspectos vinculados às ações, ambições, necessidades humanas e ao desenvolvimento. Na medida em que o homem se desenvolve no meio ambiente, os dois são inseparáveis. Neste contexto, o desenvolvimento é uma questão de "boa vizinhança" (BRUNDTLAND, 1986).

O autor continua: o desenvolvimento sustentável, então, tem papel importante, destacando que o desenvolvimento deve atender às necessidades do presente sem comprometer a capacidade de as gerações futuras atenderem, também, às suas. Conclui-se, então, que o Homem deve estar integrado ao Meio: Meio Ambiente $\leftrightarrow$ Homem. Em muitos países industrializados, o desenvolvimento implica no dever de balizar suas decisões quanto ao uso da tecnologia, pois estas poderão ter forte impacto nos países em desenvolvimento.

Muito se tem discutido sobre apropriação tecnológica (LOVINS, 1976; GOULET, 1976; CLARKE, 1986; TODD, 1989, apud LOUREIRO, 1998) e, examinando esses estudos e a literatura sobre desenvolvimento sustentável (BRUNDTLAND, 1987; COMISSÃO INTERMINISTERIAL PARA PREPARAÇÃO da ECO-92, 1991), sugere que três conceitos devam ser considerados:

a) É mais difícil para o empresário decidir em relação à apropriação de uma tecnologia do que implementar uma inovação tecnológica qualquer;

b) A percepção de necessidade de apropriação tecnológica é resultante da expectativa do empresário, da sua realização e da eficiência do produto oferecido. Muitos empresários desejam introduzir inovações tecnológicas, mas, antes de tudo, querem saber se o "novo" produto será eficiente e aceito pelo mercado;

Como se pode observar em LOILIER (1999), o ciclo de inovação tecnológica começa com a conscientização do empresário de que há uma necessidade de mudança e de que os meios para implementar esta mudança são oferecidos pela ciência. Depois de superados os problemas iniciais, surge um projeto em que as inovações vêm para refinar a tecnologia presente e é quando as empresas obtêm vantagens com a introdução da tecnologia. Finalmente, quando a nova tecnologia chega ao limite máximo de sua possibilidade de desempenho e a aceitação do produto pelo consumidor é total, atinge-se o limite de maturidade, fazendo com que o desenvolvimento diminua.

Esta situação se mantém até que surja outra que substituirá a presente por melhor eficiência ou vantagem econômica”. (LOILIER; TELLIER, 1999; p.xx. BATEMAN; SNELL, 1998, p. xx)

Conforme pesquisa realizada pelo SEBRAE (1997), no atual cenário da indústria cerâmica vermelha, existe um movimento de alguns empresários do setor que - devido ao alto consumo de energia envolvida no processo, principal fator impactante no custo do produto - procuram alternativas mais baratas e limpas, com intuito de promover maior benefício ao consumidor final, com a redução dos preços do produto e maior valor agregado ao produto.

A grande competitividade existente entre as empresas deste início de século e a busca constante da qualidade de vida por parte dos consumidores fizeram com que o aparecimento de inovações tecnológicas seguisse, progressivamente, os novos conceitos de desenvolvimento sustentável. Com a globalização, as apropriações tecnológicas são pontuais, fazendo com que os empresários se preocupem com a forma de introdução dessas apropriações e, assim, busquem modelos que indiquem, com maior precisão, qual o melhor empreendimento (HORTA; RENATO, 2006).

\section{Modelo}

O pesquisador PIDD (1998) afirma que só se pode modelar alguma coisa se for observado o entorno; e a sustentabilidade representa justamente isto: a observação de todas as coisas ao redor, para que o manejo do meio ambiente se faça sob rigorosa fiscalização.

Para elaborar um modelo de apropriação de inovação tecnológica, é necessário listar também todos os fatores que inserem os atributos relativos à apropriação tecnológica e que abrangem, inclusive, as necessidades básicas do Homem - saúde, vestuário, alimento, educação e moradia apontadas no relatório da Sra. Gro. Incluem-se, também, os indicadores de sustentabilidade apresentados pelo Fórum de Davos, 2002: a) sociais: equidade e saúde; b) econômicos: patentes e segurança; c) ambientais: atmosfera, água e solo; d) propriedades físicas; e) design.

\subsection{Medida de apropriação de inovação}

Ao tomar uma decisão de apropriação, o empresário procura visualizar as consequências advindas de cada alternativa de tomada de decisão possível. Toda a vez que ele visualiza as ações com as suas respectivas consequências, ele faz uso de um modelo mental pré-estabelecido. Porém, 
quando se trata de uma decisão a tomar relativa a um nível de complexidade maior, ele necessita avaliar corretamente a informação disponível, de forma lógica e ordenada (ANDRADE, 1989).

A partir da observação das percepções dos empresários acerca da expectativa do consumidor, são detectados alguns gaps que podem ser tecidos em atenção à entrega de um produto que o consumidor perceba como de alto nível tecnológico. Esta parte é a que se define como subjetiva, a que se constitui de valores intangíveis e, portanto, de difícil precisão. O Quadro Geral dos Gaps (Figura 2) sumariza as lacunas existentes entre a Expectativa do Consumidor e a Percepção do Empresário dessa Expectativa, bem como todos os gaps menores que envolvem as noções de cada elemento citado. Esta parte do modelo representa o sistema, os valores tangíveis (PARASURAMAN; ZEITHAML; BERRY, 1985).

Explicação dos gaps:

- GAP1 - lacuna entre as expectativas do consumidor e a percepção do empresário destas expectativas;

- GAP2 - lacuna entre a percepção do empresário e a diferença entre especificação do produto e o produto ofertado;

- GAP3 - lacuna entre a especificação do produto e o produto ofertado no final;

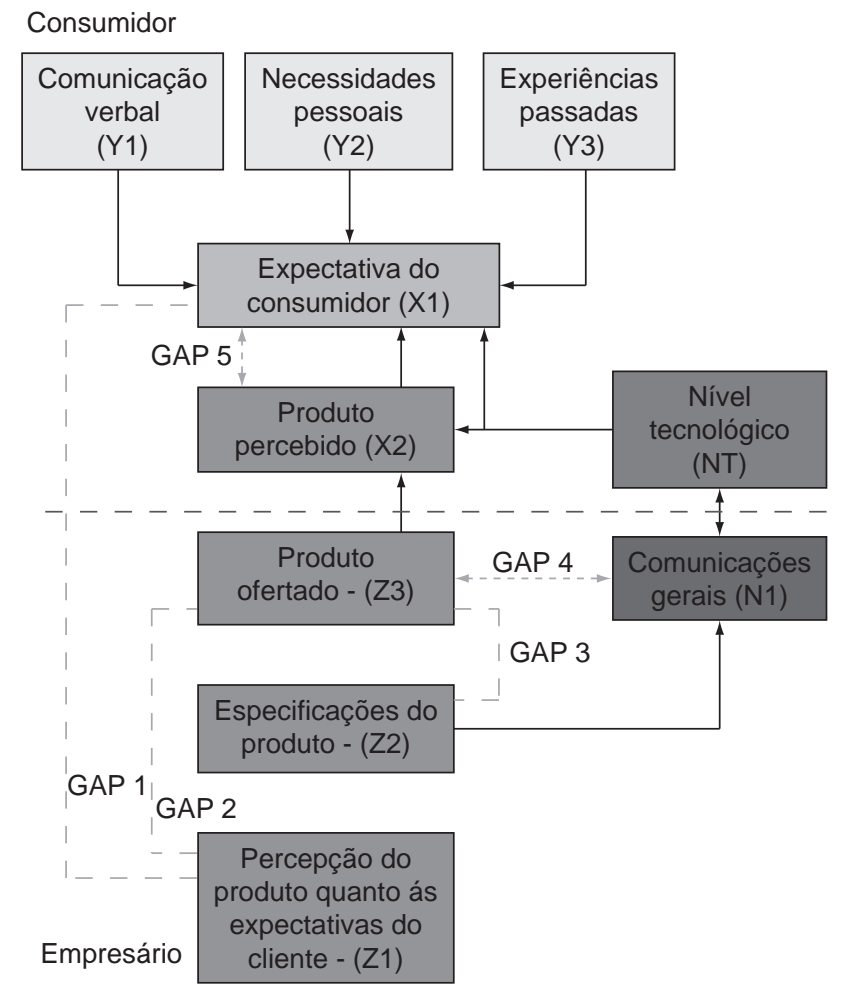

Figura 2. Quadro Geral dos Gaps. Fonte: Adaptado de Parasuraman, Zeithaml e Berry, 1985.
- GAP4 - lacuna entre as comunicações gerais acerca do produto ofertado e a performance do produto;

- GAP5 - é o gap entre a Percepção do Produto Ofertado pelo consumidor e a Percepção do empresário quanto à Expectativa do cliente em relação ao Produto Ofertado.

Indubitavelmente, a medida de acertar ou exceder a expectativa do consumidor a respeito de nível tecnológico é a chave do sucesso para quem deseja se apropriar sustentavelmente de uma inovação tecnológica. Observa-se que o gap5, na Figura 2, é o gap entre a Expectativa pelo Consumidor do Produto Ofertado e a Percepção pelo Empresário quanto as Expectativas do Cliente em relação ao Produto Ofertado, ou seja, refere-se à percepção do empresário no momento em que se conscientiza da necessidade da inovação no produto ofertado e, consequentemente, no processo de produção daquele produto. Assim, o Nível Tecnológico se define pela diferença entre a Expectativa do Consumidor (EC) e a Percepção do Produto Ofertado (PPO), que é suscetível às Comunicações Gerais, N1 (Equações 1 e 2).

$$
\begin{gathered}
\mathrm{NT}=f(\mathrm{EC}, \mathrm{PPO}) \\
\mathrm{NT}=\mathrm{EC}-\mathrm{PPO}
\end{gathered}
$$

$$
\begin{gathered}
\text { EC - Expectativa do Consumidor } \\
-\mathrm{PPO}-\text { Percepção do Produto Ofertado } \\
N T-\text { Nível Tecnológico }
\end{gathered}
$$

Expectativa do Consumidor (EC) representada por X1, que é função de: Y1 - Comunicações Verbais, referentes às expectativas comunicadas pelo consumidor ao empresário; Y2 - Necessidades Pessoais, que são aquelas expectativas não explicitadas pelo consumidor, mas percebidas pelo empresário, e Y3 - Experiências Passadas que são os valores que o consumidor já percebe no produto atual e espera que o "novo" também ofereça. Resulta, dessa forma, a Equação 3.

$$
\mathrm{X} 1=f(\mathrm{Y} 1, \mathrm{Y} 2, \mathrm{Y} 3)
$$

Obtendo-se a média aritmética dos valores da Equação 3 (Equação 4), pretende-se chegar mais perto da Expectativa do Consumidor quanto ao Nível Tecnológico do Produto Ofertado, facilitando a percepção do empresário dessa expectativa, conforme apresentado na Figura 2.

$$
\mathrm{X} 1=(\mathrm{Y} 1+\mathrm{Y} 2+\mathrm{Y} 3) / 3
$$

Percepção de Produto Ofertado (PPO) representado por (X2) é função de: Z1 - Percepção do Empresário, que se refere à percepção do empresário no momento em que se conscientiza da necessidade da inovação; Z2 - Especificações do Produto, referente às determinações das inovações tanto no produto quanto nos processos de produção pelo empresário, e Z3 - Produto Ofertado, relativo ao resultado 
efetivo no final da produção, o produto real oferecido ao consumidor. Obtém-se, assim, a Equação 5.

$$
\mathrm{X} 2=f(\mathrm{Z} 1, \mathrm{Z} 2, \mathrm{Z} 3)
$$

Percebe-se, assim, que o valor de X2 é resultado obtido a partir do momento em que o empresário se conscientiza da necessidade de inovação até o instante em que ele oferece o produto no mercado, ou seja, deve ser Z1 menos Gap2, que é a diferença entre Z2 e Z3 (Gap 3). Resulta-se, então, a Equação 6.

$$
\mathrm{X} 2=\mathrm{Z} 1-(\mathrm{Z} 2-\mathrm{Z} 3)
$$

Comunicações Gerais - quando se observa o modelo conceitual, nota-se que existe uma lacuna entre o Produto Ofertado e as Comunicações Gerais, representada por N1 - marketing, manuais, etc. As Comunicações Gerais podem afetar a Expectativa do Consumidor, não apenas na percepção produto ofertado, como suas percepções a respeito do nível tecnológico desse produto. Por meio das Comunicações Gerais, o consumidor vai dar valor ou não ao produto. Se as Comunicações Gerais forem exageradas, o consumidor poderá se decepcionar quanto às expectativas de performance do produto quando de sua utilização, não lhe atribuindo bom nível tecnológico; se as mesmas forem aquém das potencialidades de performance do produto, $\mathrm{o}$ consumidor não perceberá estes valores; ele não perceberá, portanto, seu alto nível tecnológico.

Por estes motivos, introduziu-se na Equação 4, correspondente à X1 (Expectativas do Consumidor), o N1, que corresponde ao gap das Comunicações Gerais. O N1 será o coeficiente de $\mathrm{X} 1$, porque quanto maior for o valor de N1 (Comunicações Gerais), maior será a Expectativa do Consumidor. Observem-se as Equações 7, 8 e 9.

$$
\begin{aligned}
& \mathrm{NT}=f(\mathrm{X} 1, \mathrm{X} 2, \mathrm{~N} 1) \\
& \mathrm{NT}=\mathrm{N} 1 * \mathrm{X} 1-\mathrm{X} 2
\end{aligned}
$$

Proposição final:

$$
\mathrm{NT}=\mathrm{N} 1 *[(\mathrm{Y} 1+\mathrm{Y} 2+\mathrm{Y} 3) / 3]-[\mathrm{Z} 1-(\mathrm{Z} 2-\mathrm{Z} 3)]
$$

O Modelo apresentado contempla o levantamento dos atributos valorizados pelo empresário na percepção das expectativas do consumidor, quando da utilização do produto proposto, seguindo a modelagem conceitual de Qualidade em Serviço (PARASURAMAN, 1985); o Quality Function Deployment- QFD das Quatro Fases ou das quatro matrizes que de acordo com (GUAZZI, 1999) foi desenvolvido pelo engenheiro de confiabilidade Macabe, e teve como seguidores Sullivan, Hauser e Clausing e ficou conhecido nos EUA a partir da publicação pela Harvard Business Review em 1988 do artigo "The House of Quality" de autoria de Hauser e Clausing em 1988; e a modelagem de Valor Percebido (RIBEIRO; SILVA, 2002), onde se identificam as lacunas - gaps - entre as percepções dos empresários em relação aos consumidores e, posteriormente, apresentam-se definições de ações para reforçar a competitividade empresarial. Para se avaliar o valor percebido da expectativa dos consumidores do produto da apropriação sustentável de inovação tecnológica, ao final é calculada a medida de nível tecnológico do produto avaliado.

\subsection{Componentes para percepção de apropriação de tecnologia}

Os critérios adotados seguem os atributos que devem ser notados para uma apropriação de tecnologia e as características essenciais utilizadas para a construção do modelo a partir de análise quantitativa ou qualitativa, como questionários da pesquisa de campo - empresários - e entrevistas com especialistas. Pode ser que determinada importância dos componentes característicos para a modelagem das Expectativas do Consumidor (antes do Produto Ofertado) possa diferir da importância quando da checagem da percepção do consumidor do produto ofertado.

Entretanto, há necessidade de se estabelecerem três categorias de propriedades que pareçam razoáveis ao consumidor:

- Propriedades de pesquisa - atributos que o consumidor pode avaliar antes da compra do produto;

- Propriedades de experimentação - atributos que só pedem ser avaliados no momento ou depois do consumo;

- Propriedades de credenciamento - atributo só descoberto após o consumo.

Consumidores típicos contam com propriedades de experimentação, quando avaliam apropriação de inovação tecnológica. A análise do quadro geral dos gaps (Figura 2) permite concluir que: a) quando Expectativa de Produto (EP) é maior que Percepção de Produto Ofertado (PPO): qualidade inaceitável; b) quando EP = PPO: qualidade satisfatória; c) quando EP é menor que PPO: qualidade mais que satisfatória, quase a ideal.

Logo:

$$
\begin{aligned}
& \text { EP > PPO } \mid \text { INACEITÁVEL } \\
& \text { EP }=\text { PPO } \mid \text { SATISFATÓRIO } \\
& \text { EP < PPP } \mid \text { IDEAL }
\end{aligned}
$$

\section{Aplicação da medida de nível tecnológico}

Para que a apropriação da inovação se dê dentro das diretrizes do desenvolvimento sustentável, o empresário deve contemplar as expectativas do consumidor em relação a um produto e à percepção deste produto. Para tanto, é necessário estar atento aos itens determinantes essenciais para a percepção do nível tecnológico do produto ofertado. A Figura 3 indica que a percepção da apropriação de inovação tecnológica é resultado da comparação da Expectativa do 
Consumidor em relação ao Produto Ofertado quando da apropriação e da percepção dessa apropriação.

Em essência, os executivos nem sempre podem entender quais são as características de alto nível tecnológico high tech - para os consumidores de ponta; que características o produto tem de ter para ir ao encontro da expectativa do cliente, e qual o nível de desempenho destas características é necessário para oferecer um produto de alto nível tecnológico. Esta percepção pode ser esclarecida com pesquisa prévia do produto, a qual sugere que os empresários nem sempre entendem o que o consumidor espera. Esse ponto de entendimento pode afetar a percepção pelo consumidor do produto ofertado. Tudo vai ser de acordo com as comunicações gerais que o empresário vai determinar a respeito de seu produto.

O Caso estudado para aplicação da Medida de Nível Tecnológico para Apropriação Sustentável de Inovação foi a Indústria de Cerâmica Vermelha do Estado do Rio de Janeiro, por meio do intercâmbio cultural realizado entre o Centro Federal de Educação Tecnológica Celso Suckow da Fonseca (CEFET/RJ) e pelo Instituto de Tecnologia para os Trópicos (ITT) da Fachhochschule/Köln, na Alemanha, no âmbito do intercâmbio CAPES, Brasil, e do DAAD, Alemanha.

A abordagem está organizada em sete etapas principais:

1) Levantamento de atributos específicos em relação à apropriação sustentável de inovação tecnológica. No estudo de caso da tecnologia de alta porosidade aplicada do tijolo estrutural de cerâmica vermelha alemã apropriada à indústria fluminense, esses atributos foram levantados a partir da revisão bibliográfica, da pesquisa de campo e entrevistas com os especialistas;
2) Levantamento de valor atribuído pelos consumidores e pelos empresários para os diversos atributos e seus respectivos níveis tecnológicos. Esses dados foram obtidos a partir de entrevistas com especialistas e de pesquisas de campo;

3) Estruturação de um modelo conceitual da apropriação sustentável de inovação tecnológica. Esse modelo é construído a partir de entrevistas com especialistas e das etapas anteriores;

4) Estabelecimento de um modelo matemático para o valor percebido da expectativa dos clientes; no caso da indústria cerâmica vermelha, podem-se definir vários clientes: o consumidor final, que é a sociedade que utiliza as edificações construídas com alvenarias de tijolos de cerâmica vermelha; o construtor das edificações, e o projetista da edificação. No estudo de caso, a percepção dos clientes da indústria ceramista foi levantada por meio de consulta a especialistas.

5) Estabelecimento de um modelo matemático para o valor da percepção do empresário quanto à expectativa do consumidor do produto resultante de apropriação sustentável de inovação tecnológica;

6) Comparação entre o valor de percepção pelo empresário de apropriação sustentável de inovação tecnológica e o valor percebido pelo consumidor do produto dessa apropriação;

7) Estabelecer o valor que será atribuído às comunicações gerais, a fim de se calcular a medida de nível tecnológico do produto final.

A partir dos resultados obtidos, o empresário pode definir várias ações que irão reforçar sua decisão acerca da apropriação de inovação tecnológica.

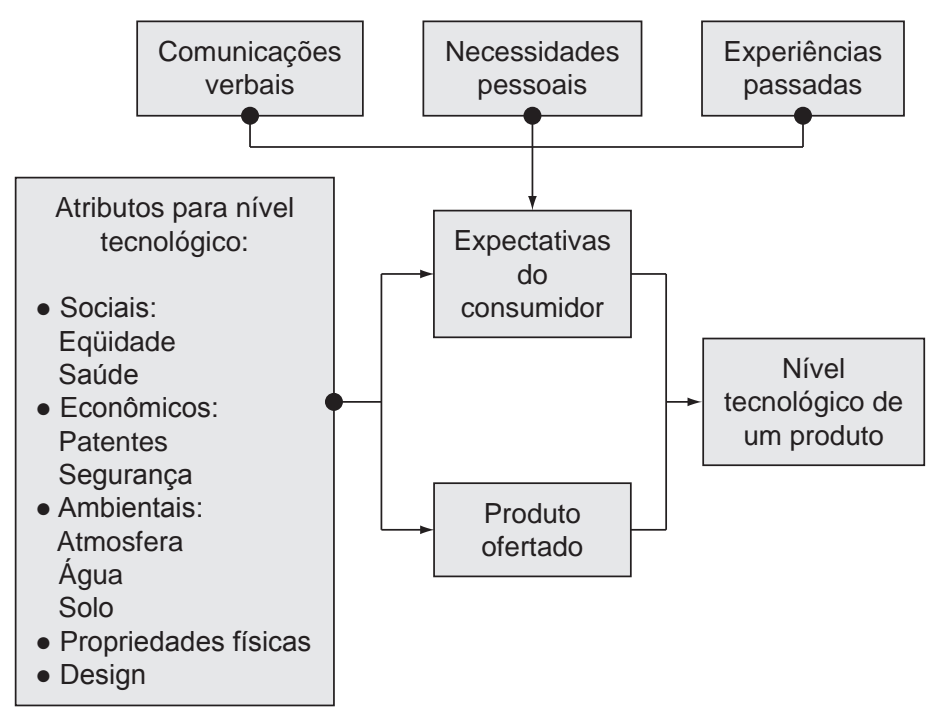

Figura 3. Quadro dos atributos de apropriação de inovação tecnológica. Fonte: Adaptado de Parasuraman, Zeithaml e Berry, 1985. 


\subsection{Pesquisa de campo: ceramistas e especialistas}

Para aplicação da Medida de Nível Tecnológico para apropriação de inovação, foi necessária a realização de uma pesquisa de campo que, num primeiro momento, envolveu visitas técnicas e estágios supervisionados à Alemanha, quando professores e alunos integrantes do intercâmbio tiveram a oportunidade de conhecer a tecnologia alemã para produção de blocos estruturais de alta porosidade (CLETO et al., 2000).

De volta ao Brasil, o grupo participante do intercâmbio com a Alemanha, junto a novos pesquisadores, realizou uma pesquisa de campo em 12 empresas do setor ceramista do Estado do Rio de Janeiro, utilizando-se para isto um vasto questionário multidisciplinar Relatório Projeto Cerâmica - CEFET/RJ (BROCHADO et al, 2004).

\subsection{Levantamento dos Atributos}

O levantamento dos atributos pertinentes ao estudo de caso, bem como dos valores de cada atributo, foram realizados a partir das entrevistas com 12 empresários do Setor de Cerâmica Vermelha do Estado do Rio de Janeiro e de um grupo multidisciplinar de especialistas. Este grupo foi composto de pesquisadores, ceramistas participantes da Associação dos Ceramistas, proprietários de lojas de produtos de construção civil (ANICER) e profissionais do Setor que compõem o Projeto citado.

A partir da entrevista com especialistas por meio de aplicação de um questionário, foi gerada uma planilha, na qual eles conferiram notas de zero a dez a cada atributo relativo à apropriação de tecnologia para o caso da apropriação tecnológica do tijolo estrutural de alta porosidade de cerâmica vermelha - padrão alemão. Estes dados foram listados, tendo a média e o desvio padrão calculados em planilha Excel, para operacionalizar a equação de nível tecnológico da indústria brasileira em relação à indústria alemã. Obteve-se a Equação 10:

em que:

$$
\mathrm{NT}=\left(\mathrm{N}_{1} \times \mathrm{X}_{1}\right)-\mathrm{X}_{2}
$$

$$
X_{1}=\frac{\left(Y_{1}+Y_{2}+Y_{3}\right)}{3} \text { e } \mathrm{X}_{2}=\mathrm{Z}_{1}-\left(\mathrm{Z}_{2}-\mathrm{Z}_{3}\right)
$$

Aplicando-se estes atributos à equação de Nível Tecnológico, seguindo os critérios adotados na construção do questionário aplicado aos especialistas, foram definidos:

Para X1 - Expectativas do Consumidor, em relação ao produto ofertado:

a) Comunicações Verbais - Y1:

- Qual é o valor percebido da resistência à compressão do tijolo?

- Qual é o valor percebido para a utilização do tijolo em construção de casa própria?
- Qual é o valor percebido para cuidado ambiental demonstrado pelo empresário?

b) Necessidades Pessoais - Y2:

- Qual é o valor percebido da porosidade aparente do tijolo?

- Qual é o valor percebido da densidade da peça?

- Qual é o valor percebido da condutância térmica da peça?

- Qual é o valor percebido do tijolo para abrigo contra intempéries?

c) Experiências Passadas - Y3:

- Qual é o valor percebido da resistência à compressão do tijolo?

- Qual é o valor percebido para os recursos humanos do local?

- Qual é o valor percebido para a utilidade do produto do tijolo apropriado?

Para X2 - Percepção sobre Produto Ofertado -, estabeleceram-se alguns atributos específicos para o planejamento estratégico organizacional:

a) Percepção do Empresário - Z1:

- Qual é o valor percebido para formação profissional no processo de inovação?

- Qual é o valor percebido para o ciclo de vida do produto?

- Qual é o valor percebido para o reaproveitamento de insumos?

- Qual é o valor percebido para conservação energética na produção?

- Qual é o valor percebido para a segurança do trabalho?

- Qual é o valor percebido para as políticas públicas?

- Qual é o valor percebido para a busca de inovação tecnológica?

- Qual é o valor percebido do tijolo para abrigo contra intempéries?

b) Especificações do Produto - Z2:

- Qual é o valor percebido para a extração da argila?

- Qual é o valor percebido para recuperação do solo onde se encontra a jazida?

- Quais são os valores percebidos para os insumos?

- Qual é o valor percebido para utilização da água?

- Quais são os valores percebidos para o processo de tratamento?

- Quais são os valores percebidos para as etapas do processo da mistura?

a - Trituração: b - Mistura: c - Laminação:

- Quais são os valores percebidos para o processo de secagem?

- Quais são os valores percebidos para o processo de queima?

$\mathrm{a}$ - Energia: $\mathrm{b}$ - Forno: $\mathrm{c}$ - Tempo: 
- Qual é o valor percebido para emissão de carbono no processo de queima?

- Quais são os valores percebidos para as perdas de material no processo?

c) Produto Ofertado - Z3:

- Qual é o valor percebido da porosidade aparente do tijolo?

- Qual é o valor percebido da resistência à compressão do tijolo?

- Qual é o valor percebido da densidade do tijolo?

- Qual é o valor percebido da condutância térmica da peça?

\subsection{Estudo comparativo de nível tecnológico da indústrias de cerâmica vermelha alemã e brasileira}

Depois de lançados todos os valores obtidos a partir do questionário com os especialistas para as planilhas,

Tabela 1. Médias dos atributos de apropriação sustentável de tecnologia na indústria de cerâmica

\begin{tabular}{cc}
$\begin{array}{c}\text { Z1 Bras. (médio) } \\
\text { 3,04 }\end{array}$ & Z1 Alemão (médio) \\
Z2 Bras. (médio) & Z2 Alemão (médio) \\
5,02 & 8,84 \\
Z3 Bras. (médio) & Z3 Alemão (médio) \\
3,29 & 8,50 \\
Y1 Bras. (médio) & Y1 Alemão (médio) \\
6,33 & 9,13 \\
Y2 Bras. (médio) & Y2 Alemão (médio) \\
2,89 & 8,99 \\
Y3 Bras. (médio) & Y3 Alemão (médio) \\
4,35 & 9,19 \\
\hline
\end{tabular}

tiradas as médias, calculado o desvio padrão no programa Microsoft ${ }^{\circledR}$ Excel, foi elaborada a Tabela 1, para demonstrar as médias dos valores Z1- Percepção das Expectativas do Consumidor; Z2 - Especificações do Produto; Z3 - Produto ofertado; Y1 - Comunicações Verbais; Y2 - Necessidades Pessoais, e Y3 - Experiências Passadas por parte do Consumidor, para o Brasil e para a Alemanha.

\section{A) N1-Gap 4 das comunicações gerais sobre o Produto (design, marketing, manuais, etc.)}

Se as expectativas do consumidor são muitas, é porque a empresa prometeu muito: logo, ela deverá corresponder a estas expectativas. A decepção quanto às expectativas em demasia não deixará o consumidor perceber o nível tecnológico ofertado (PARASURAMAN et al., 1988). Pode, ainda, ocorrer frustração de expectativa do cliente, se a empresa não oferecer conhecimentos básicos para a utilização correta do produto.

No Brasil, os primeiros atrativos em relação ao marketing podem girar em torno do lançamento da técnica construtiva do ECOPOP, que consiste na adaptação da tecnologia alemã de tijolo estrutural de cerâmica vermelha de alta porosidade para um modelo fluminense, fabricado no Estado do Rio de Janeiro, para a execução de habitações com alvenaria estrutural, utilizando-se o tijolo estrutural de cerâmica vermelha de alta porosidade, fruto da pesquisa da especialista Glória Maria Monetto, em sua Dissertação de Mestrado (MONETTO e BROCHADO, 2004).

Comunicações externas podem afetar não apenas as expectativas do cliente em relação ao produto ofertado, mas também as percepções do consumidor a respeito do nível tecnológico deste produto. Concomitantemente, discrepâncias entre Produto Ofertado e Comunicações Gerais, em forma de exageradas promessas e/ou ausência de informação acerca do

Tabela 2. Quadro da simulação de N1 com notas de 1 a 10.

\begin{tabular}{|c|c|c|c|c|}
\hline \multicolumn{3}{|c|}{ NT Brasileiro } & \multicolumn{2}{|l|}{ NT Alemão } \\
\hline $\mathrm{X} 1=(\mathrm{Y} 1+\mathrm{Y} 2+\mathrm{Y} 3) / 3$ & \multicolumn{2}{|c|}{ X2 = Z1-(Z2-Z3) } & $\mathrm{X} 1=(\mathrm{Y} 1+\mathrm{Y} 2+\mathrm{Y} 3) / 3$ & X2 = Z1-(Z2-Z3) \\
\hline 4,53 & \multicolumn{2}{|c|}{1,30} & 9,10 & 8,95 \\
\hline $\mathrm{X} 1=(6,33+2,89+4,35) / 3$ & \multicolumn{2}{|c|}{$X 2=3,04-(5,02-3,29)$} & $\mathrm{X} 1=(9,13+8,99+9,19) / 3$ & $X 2=9,29-(8,84-8,5)$ \\
\hline 4,53 & \multicolumn{2}{|c|}{1,30} & 9,10 & 8,95 \\
\hline N1 & - & $\begin{array}{c}\mathrm{NT}=(\mathrm{N} 1 * \mathrm{X} 1)-\mathrm{X} 2 \\
\text { Brasileiro }\end{array}$ & & $\begin{array}{c}\mathrm{NT}=(\mathrm{N} 1 * \mathrm{X} 1)-\mathrm{X} 2 \\
\text { Alemão }\end{array}$ \\
\hline 1 & 4,53 & 3,22 & 9,10 & 0,15 \\
\hline 2 & 9,05 & 7,75 & 18,20 & 9,25 \\
\hline 3 & 13,58 & 12,27 & 27,30 & 18,35 \\
\hline 4 & 18,10 & 16,80 & 36,40 & 27,45 \\
\hline 5 & 22,63 & 21,32 & 45,50 & 36,55 \\
\hline 6 & 27,15 & 25,85 & 54,60 & 45,65 \\
\hline 7 & 31,68 & 30,37 & 63,70 & 54,75 \\
\hline 8 & 36,20 & 34,90 & 72,80 & 63,85 \\
\hline 9 & 40,73 & 39,42 & 81,90 & 72,95 \\
\hline 10 & 45,25 & 43,95 & 91,00 & 82,05 \\
\hline
\end{tabular}




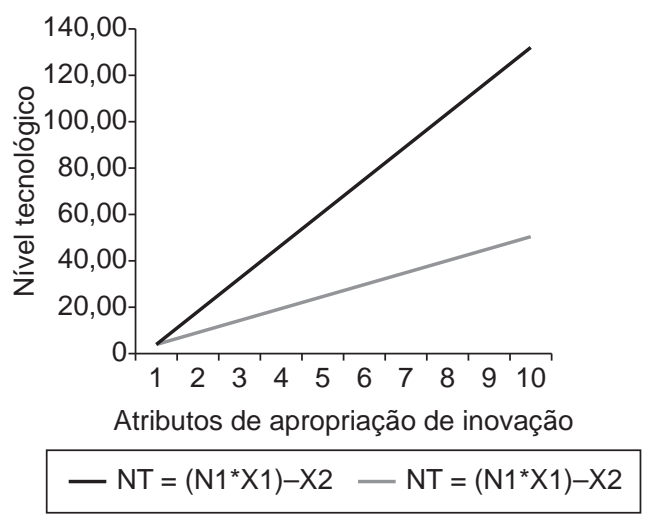

Gráfico 1. Gráfico da Função de Nível Tecnológico Alemão e Brasileiro, na Indústria Cerâmica Vermelha. Fonte: Bastos (2004).

Produto Ofertado, afetarão a percepção do Nível Tecnológico deste produto (PARASURAMAN et al., 1988).

Sendo este um valor muito variável, foi feita a simulação das equações tomando como base os valores de um a dez, em que se obtiveram os variados resultados, conforme Tabela 2.

A partir da tabela 2, foi construído o gráfico 1, que demonstra a curva de nível tecnológico da tecnologia de alta porosidade padrão alemão, quando colocada ao lado da curva de nível tecnológico da cerâmica vermelha fluminense.

O gráfico que surgiu em função dos atributos de apropriação de inovação valida o alto Nível Tecnológico da Indústria Cerâmica Vermelha da Alemanha em relação à Indústria Fluminense. Isso demonstra a importância de se atribuir valor para as Comunicações Gerais, a qual determinará se as Expectativas do consumidor foram contempladas. Observa-se que a Expectativa do Cliente sofre alterações de acordo com o alto ou baixo valor atribuído às Comunicações Gerais (BASTOS, 2004).

a) quando Expectativa do Consumidor é maior que Percepção de Produto Ofertado: Nível Tecnológico inaceitável:

\section{EC > PPO | NT INACEITÁVEL;}

b) quando Expectativa do consumidor, igual à Percepção de Produto Ofertado: Nivel Tecnológico satisfatório:

\section{$\mathrm{EC}=\mathrm{PPO} \mid$ NT SATISFATÓRIO;}

c) quando Expectativa do Consumidor é menor que Percepção de Produto Ofertado: Nivel Tecnológico mais que satisfatória:

\section{EC < PPO | NT IDEAL / HIGH TECH.}

A avaliação comparativa dos resultados referenciados às Expectativas do Consumidor, no modelo dos Gaps, torna os resultados sempre atrelados às perspectivas de mudanças do mercado com a visão dinâmica das modificações e evoluções das expectativas dos clientes das empresas. Essa abordagem refere-se à facilidade no entendimento dos itens da escala, já que todos eles estão associados a produtos, serviços e outros atributos perfeitamente observáveis pelos consumidores durante o processo de utilização de produtos e serviços.

Por fim, apresentam-se as vantagens e as restrições do modelo proposto para a indústria cerâmica vermelha. A principal vantagem observada refere-se ao conhecimento das necessidades do cliente a ser considerado nas decisões empresariais. Por outro lado, esses modelos apresentam alguns problemas operacionais. Como as operações de diversas empresas têm particularidades que as diferenciam de região para região, pode haver problemas para mensurar essas disparidades e, principalmente, para agregar as diferenças em um único indicador de desempenho percebido pelo consumidor.

Além disso, o tempo de aplicação normalmente é longo, dado que, em muitos casos, se aplica a escala duas vezes (uma para medir as expectativas e outra para mensurar a performance), o que torna a coleta mais complexa e a aplicação mais cansativa para os respondentes. Existe, ainda, a dificuldade de sumariar em um indicador único de Satisfação, sem que sejam árbitra dos pesos às dimensões. Isso significa que os resultados finais obtidos nesse processo podem ser questionados pela arbitrariedade de estipulação dos pesos, que podem não ser de concordância de todas as empresas e/ou participantes do processo de avaliação.

\section{Conclusão}

Os modelos baseados na teoria da desconformidade visam, principalmente, a avaliação por atributos, que permitem verificar particularidades da operação das empresas. Oferecem a possibilidade de trabalhar com indicadores operacionais para a empresa e seus diversos setores. A Medida de Nível Tecnológico da inovação estabelece o valor percebido do nível tecnológico de um produto por parte do cliente, com a finalidade de auxiliar a tomada de decisão de apropriação sustentável de tecnologia por parte do empresário. De acordo com o nível tecnológico observado na proposta, é possível conduzir a empresa a uma melhor adaptação no mercado em que atua, otimizando esforços na busca de sua inserção na cultura de inovação, que permite mudança na tecnologia, no processo, na estrutura organizacional e, principalmente, na qualificação dos recursos humanos e ambientais.

Devido à generalidade das etapas que compõem esta proposta, acredita-se que esta possa ser muito utilizada no processo de planejamento de inovação de qualquer indústria. As organizações voltadas ao processo do planejamento de inovação tecnológica, em um contexto sustentável, podem alcançar uma vantagem competitiva, fazendo uso da abordagem proposta. Ela pode ser usada para subsidiar as decisões referentes a investimentos a serem efetuados em inovações, buscando continuamente a melhor relação custo-benefício para as empresas e seus parceiros. Como conclusão, ao atender ou superar a expectativa do cliente no nível tecnológico, é alcançada a chave do sucesso para quem deseja se apropriar de uma inovação tecnológica. 


\title{
Technological appropriation model: the red brick industry case
}

\begin{abstract}
In the last years, the accelerated rhythm of the technological innovations has been causing social, political, cultural, ecological and economic impact in the nations. In the eighties and nineties, a commission of UN had the responsibility of bringing up the problems that mankind would have in the coming decades, which subsidized the Conference of the United Nations about Environment and Development - ECO - 1992. At this meeting, 179 countries signed a calendar of commitments for the XXI century, the XXI Agenda, and presented the eco-efficient proposal to aid the companies in the environmental planning, approaching a new dimension of competitiveness: to produce with efficiency, using less input and generating less rejects. Besides this need of environmental conservation, human beings are demanding that the companies get hold of the existing high technologies - high tech - in other countries. Even so, depending on the level of development of the countries, the managers must proceed carefully so native users will be prepared to absorb these innovations. Starting from the service quality modeling, this work presents the measure propose of technological innovation level that investigates the necessary ways to technological appropriation and defines a methodology to calculate technological level in decision makings concerning innovation appropriation. The applied case study is in the red ceramic industry, in Brazil, with appropriation of German technology of manufacture of structural red ceramics bricks with high porosity, in which are identified gaps - the existent gaps between the consumer's expectation and its perception in relation to the offering product; these gaps delineates the technological profile of the product. The model test demonstrates that the innovation process in the organizations should be implanted starting from a strategic planning process that considers the cycles of technology life and future innovations, which leads to the fact that the proposed modeling aids companies concerning appropriation of technological innovation from a sustainable environment.
\end{abstract}

Keywords: Technological innovations. Technological appropriation. Red brick.

\section{Referências bibliográficas}

ANDRADE, E. L. Introdução a pesquisa operacional: métodos e técnicas para a análise de decisão. Rio de Janeiro: Ed. LTC, 1989.

BASTOS, S. S. Modelo conceitual de nível tecnológico para apropriação sustentável de inovação: caso da indústria cerâmica vermelha. Rio de Janeiro, 2004. Dissertação (Mestrado em Tecnologia) - Centro Federal de Educação Tecnológica - CEFET.

BATEMAN, T. S.; SNELL, S. A. Administração. Construindo vantagem competitiva. Tradução de Celso A. Rimoli. São Paulo: Ed. Atlas S. A., 1998.

BROCHADO, M. R. et al. Estudo sobre os Impactos da Tecnologia Poroton na Indústria da Cerâmica no Estado do Rio de Janeiro. XX Encontro Nacional de Engenharia de Produção. São Paulo - SP, 2000.

BROCHADO, M. R. et al. Diretrizes para Pesquisa de Mercado de uma Inovaçao Tecnológica. In: XXI Encontro Nacional de Engenharia de Produção, 2001, Salvador. Engep 2001. Porto Alegre: Associação Brasileira de Engenharia de Produção, 2001. v. 1

BROCHADO, M. et al. Rio $92+10$ : um exemplo bem sucedido de cooperação norte-sul no desenvolvimento sustentável na área da cerâmica vermelha In: ENCONTRO NACIONAL DE ENGENHARIA DE PRODUÇÃO - ENEGEP, 2002, São Paulo. Anais...

M. R. et al. O perfil tecnológico da indústria de cerâmica vermelha do Estado do Rio de Janeiro. Rio de Janeiro: SEBRAE, 2004.
BRUNDTLAND, G. H. et al. Nosso futuro comum. Rio de Janeiro: Fundação Getúlio Vargas, 1986.

CLETO, S. S. et al. Relatório técnico comparativo da indústria de cerâmica vermelha Brasil - Alemanha. Rio de Janeiro: Centro Federal de Educação Tecnológica - CEFET, 2000.

COMISSÃO INTERMINISTERIAL PARA PREPARAÇÃO DA ECO-92. O desafio do desenvolvimento sustentável. Brasília: Governo do Brasil, 1991. (Relatório do Brasil para a Conferência das Nações Unidas Sobre Meio Ambiente).

GONZÁLEZ, R. F. L. Lo cualitativo y lo cuantitativo en la investigación de la psicología social. Revista Psicologia \& Sociedade, v. 10, n. 2, p. 32-52, jul./dez. 1998.

GUAZZI, D. M. Utilização do QFD como uma Ferramenta de Melhoria Contínua do Grau de satisfação de Clientes Internos: Uma Aplicação em Cooperativas Agropecuárias. Tese de Doutorado em Engenharia de Produção - UFSC. Florianópolis, SC, Brasil, 1999.

HAUSER, J. R.; CLAUSING, D. The House of Quality. Harvard Business Review, p. 63-73, may- june 1988.

HORTA, R.; RENATO, P. Cultura organizacional e gestão da inovação tecnológica. Disponível em:< http://www. institutoinovacao.com.br/internas/artigo/idioma/1/169/Cultura +Organizacional+e+Gestao+da+Inovacao+Tecnologica. Acesso em: Dezembro 2006.

LOILIER, T.; TELLIER, A. Gestion de L'Innovation. Caen, França: Éditions Management, 1999.

LOUREIRO, J. L. Tecnologias apropriadas como alternativa de desenvolvimento tecnológico para países subdesenvolvidos. 
Rio de Janeiro, 1998. Dissertação (Mestrado) - COCPG, Centro Federal de Educação Tecnológica - CEFET.

MARX, K.; ENGELS, F. Manifesto do partido comunista. [S.1.]: [s.n.], 1848.

MONETTO, G. M., BROCHADO, M. R. A aplicação do ECOPOP a EcoCerâmica vermelha de alta porosidade, em projetos de habitações populares. Rio de Janeiro: Centro Federal de Educação Tecnológica - CEFET, 2004.

MONTAÑA, J. Innovación: el reto empresarial del siglo XXI. In: El arte de innovar en la empresa. Antoni M. Güell y Mar Vila (Coord.). JORNADA ANUAL - ESADE, v. 7, Madri, Espana, 2002.

PARASURAMAN, A.; ZEITHAML, V. A.; BERRY, L. L. A conceptual model of service quality and its implications for future research. Journal of Marketing, v. 49,p. 41 - 50, 1985.

PARASURAMAN, A.; ZEITHAML, V. A.; BERRY, L. L. SERVQUAL: A multiple-item scale for measuring consumer perceptions of service quality. Journal of Retailing,, v. 64, n. 1, 1988.

PEIXOTO, M. O.; CARPINETTI, L. C. Quality Function Deployment - QFD. 1998. Disponível em:www.numa.org./ brconhecimentos/conhecimentos/QFD.
PIDD, M. Modelagem empresarial. Ferramentas para tomada de decisão. Tradução de Gustavo Severo et al. Porto Alegre: Editora de Artes Médicas Sul Ltda, 1998.

PIRES, H. F. Inovação tecnológica e desenvolvimento da Cibercidade: O advento da Cibercidade. In: CONFERÊNCIA INTERNACIONAL CYBERCITY, 2003, São Paulo.

PONTUAL, H. D. Entenda o fórum econômico mundial. Disponível em:<http://www.senado.gov.br/web/comunica/ agencia/entenda/forum_economico_mundial.htm>. Acesso em: 12 Janeiro 2006.

RIBEIRO, J. L. D.; SILVA, P. R. C. Uma proposta para a modelagem do valor percebido na prestação de serviços. Revista de Produção, v. 12, n. 1, 2002.

SERVIÇO DE APOIO ÀS MICRO E PEQUENAS EMPRESA SEBRAE. Relatório final conservação de energia: estudos setoriais aspectos econômicos e tecnológicos - setor de cerâmica vermelha. Rio de Janeiro, 1997.

Sobre os autores

\section{Simone de Sá Bastos}

Centro Federal de Educação Tecnológica Celso Suckow da Fonseca - CEFET/RJ

Av. Maracanã, 229, Bloco E, 5ㅇandar, CEP 20271-110, Rio de Janeiro - RJ, Brasil

e-mail: samone@cefet-rj.br

\section{Marina Rodrigues Brochado}

Centro Federal de Educação Tecnológica Celso Suckow da Fonseca - CEFET/RJ Av. Maracanã, 229, Bloco E, 5ㅇandar, CEP 20271-110, Rio de Janeiro - RJ, Brasil e-mail: marina@cefet-rj.br 